\title{
Inter- and intraclonal variability in the photoperiodic response and fecundity in the pea aphid Acyrthosiphon pisum (Hemiptera: Aphididae)
}

\author{
NADEZHDA ERLYKOVA \\ Laboratory of Experimental Entomology, Zoological Institute, Russian Academy of Sciences, St.Petersburg 199034, Russia; e-mail: \\ ne@NE4433.spb.edu
}

Key words. Aphids, photoperiodism, Acyrthosiphon pisum, pea aphid, polymorphism, clone, clonal variation, reproduction, fecundity, migrants, parthenogenesis, annual cycle, seasonal development

\begin{abstract}
Interclonal variability in the photoperiodic responses of the pea aphid Acyrthosiphon pisum and intraclonal differences between wingless viviparous females (=apterae) and winged viviparous females (=alatae) were studied. In 7 clones collected from peas near St.Petersburg the effect of constant diel photoperiods (from $0 \mathrm{~L}: 24 \mathrm{D}$ to $24 \mathrm{~L}: 0 \mathrm{D}$ at $20^{\circ} \mathrm{C}$ ) on sexual morph determination and dynamics of morph production were recorded. Apterae of 5 clones and apterae and alatae of 2 clones were studied. The mean and age-dependent fecundity of apterae and alatae were compared. The clones studied in detail can be divided in two groups. The first includes clones that produced winged males and had critical photoperiods for female morph determination around $12 \mathrm{~L}: 12 \mathrm{D}$. The second includes clones with critical photoperiods for female morph determination around 17L : 7D; these clones produced wingless males, and one clone produced only oviparae. The intraclonal differences in the photoperiodic limits for ovipara and male production depended on the clone-specific abundance of males. The shapes of the photoperiodic curves for male production also depended on the clone-specific abundance of males. In short-day conditions alatae produced more oviparae and fewer males, and the range of photoperiods that induced ovipara production in alatae was nearly twice as wide as that in apterae. The photoperiodic limits for ovipara and male production differed for apterae and alatae. The fecundity of alatae was lower, although they reproduced for longer and lived longer than apterae. Both apterae and alatae reproduced more intensively over the first 2 weeks. Apterae and alatae began to produce males at the same age. Because of their late onset of larviposition, the reproductive pause that divides female and male production was obscured in alatae. Both apterae and alatae tended to produce initially and finally batches of viviparous offspring, possibly reflecting age-dependent endogenous changes in the hormonal titres in the parents.
\end{abstract}

\section{INTRODUCTION}

Photoperiodic regulation of the switch from parthenogenetic to sexual reproduction in aphids has been extensively studied for nearly 80 years. However, the detailed reports are generally based on an analysis of single clones (Lees, 1963, 1989; Lamb \& Pointing, 1975; Zaslavski \& Fomenko, 1983, 1986; MacKay, 1987). The simultaneous analysis of several aphid clones sometimes revealed the existence of local interclonal variability in the photoperiodic response (Blackman, 1971; Eisenbach \& Mittler, 1987; Takada, 1988; MacKay, 1989; Smith \& MacKay, 1989a, 1990; Mittler \& Wilhoit, 1990; Mittler \& Gorder, 1991; Lamb \& MacKay, 1997; Dedryver et al., 1998), but usually only a few photoperiods were used. The photoperiodic response curves for male and ovipara production in the pea aphid Acyrthosiphon pisum (Harris) over the complete range of photoperiods is known for one clone from Cambridge (Lees, 1989). The object of the present work was to estimate the interclonal variability in the photoperiodic response of the green form of the pea aphid from the Leningrad Province, the northernmost population studied to date, and to determine the intraclonal differences in the responses shown by apterae and alatae.

\section{MATERIAL AND METHODS}

Pea aphids develop on legumes and are normally holocyclic in severe climates. A fundatrix hatches in spring from an overwintering egg and gives birth to a parthenogenetic generation of wingless viviparous females (=apterae). In addition, winged viviparous females (=alatae) appear in summer. They migrate and form new parthenogenetic colonies on host plants of the same or related species. In autumn, the viviparae produce a sexual generation consisting of males and ovipositing females (=oviparae). The oviparae lay fertilized eggs, which diapause over winter.

Clones of the green form of the pea aphid were collected from peas near St. Petersburg, $60^{\circ} \mathrm{N}$, in August 1994 (clone B) and August 1995 (C, D, E, F, G and H). Each clone was initiated from single female. The effect of constant diel photoperiods on the sexual morph of the offspring and on the dynamics of offspring morph production in time was studied in apterae of all the clones. In addition, the variability in these characters in alatae was studied in clones $\mathrm{E}$ and $\mathrm{F}$. The mean and agedependent fecundity of apterae and alatae were also compared.

The stock culture was reared on Vicia faba seedlings at $20 \mathrm{~L}$ : $4 \mathrm{D}$ and $20^{\circ} \mathrm{C}$. The method of prenatal aphid exposure to experimental photoperiods developed by Lees (1963) and modified by the author (Erlykova, 1999) was used. A 7-day old grandparents were placed in experimental photoperiods at $20^{\circ} \mathrm{C}$. The parent generation was collected 7 days later during the 6-8 hour light period and kept under the same experimental conditions. A group of 10-20 (commonly 15) parent females was reared in each regime. The larvae produced by a group of females were usually collected every other day, a total of 8-9 batches over the whole reproductive period. Morphs were identified when the aphids became adult. 

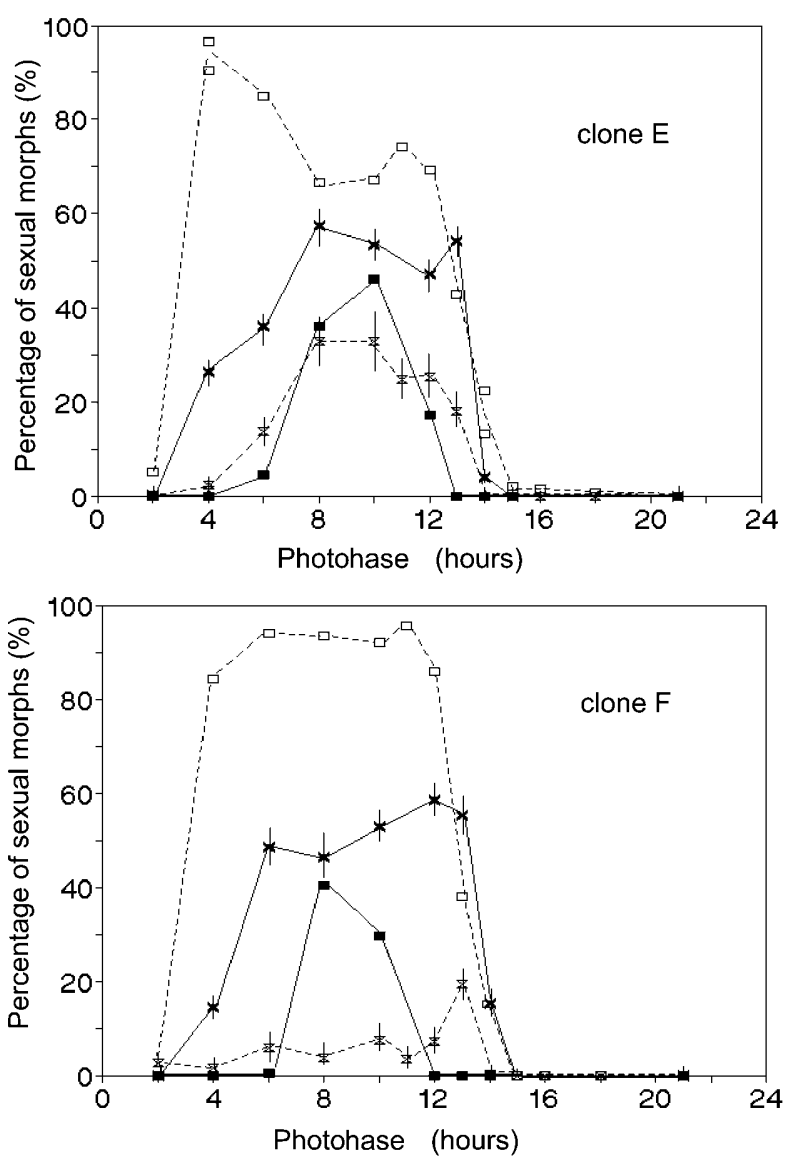

Fig. 1. The relationships between photoperiod and production of sexual morphs for apterae (solid line) and alatae (dashed line) of A. pisum. Oviparae indicated by filled and empty squares, males by $\mathrm{X}$ and hourglasses. Vertical bars indicate confidence intervals for males.

\section{RESULTS}

\section{Interclonal differences in the effect of photoperiod on sex and female morph determination}

Apterae of all clones produced viviparae when reared under long-day and extremely short-day conditions. In the short days predominantly oviparae were produced, although viviparae were produced sometimes at $20^{\circ} \mathrm{C}$ (Table 1). Thus, the photoperiodic response curves for female morph determination have two transitional zones (or zones of intermediate photoperiod, according to Lees, 1959) when both viviparae and oviparae occur among the offspring. The range of the transitional photoperiods is about $90 \mathrm{~min}$ for natural photoperiods and somewhat wider for extremely short photoperiods. Thus, the changes in progeny composition at transitional photoperiods occurred sharply in a threshold-like response (Zaslavski, 1988) and all clones showed a threshold long-day response for female morph determination.

The critical photoperiod is the photoperiod that corresponds to the mid-percentage of viviparae production in the threshold zone of response curve (according to Zaslavski, 1988). It does not correspond to $50 \%$ viviparae in the progeny because apterae of clones B, D, E, F and G produced some viviparae under short-day conditions (Table 1). In the present study the photoperiodic response was expressed as the percentage of each morph in the progeny, not the percentage of parents that produce each morph. As the range of transitional photoperiods was small (threshold-like), the values for the critical photoperiods based on these two definitions are very similar (Lamb \& Pointing, 1972).

The critical photoperiod in the range of natural photoperiod was near to $12 \mathrm{~L}: 12 \mathrm{D}$ in clones $\mathrm{C}, \mathrm{D}, \mathrm{E}, \mathrm{F}, \mathrm{H}$ and 17L : 7D in clones $B$ and $G$ (Table 2). Thus, the difference in the critical photoperiods for female morph determination in these two groups of clones is obvious.

The critical photoperiods for clones $B$ and $G$ under extremely short-day conditions were correspondingly shorter than those of clones C, D, E, F and H (Table 2).

The patterns of male and ovipara production clearly depended upon the clone, and the photoperiods that favoured the maximum production of sexuals varied between clones (Table 2). There were clones in which males constituted a significant part of the progeny (clones E, F), and clones that produced few males. If the percentage of males in the progeny was low it was not possible to determine the critical photoperiod for male production. The peak of male production was, as a rule, induced by longer photoperiods than for oviparae. If a clone produced predominantly males in short-day conditions, the photoperiod that induced the production of males was about 2 hours (clone E) or more (clone F) longer than that which induced the production of oviparae. For the clones that produced predominantly oviparae in short-day conditions, the difference in the photoperiods that induced the production of males and oviparae was about an hour (clones C, D, and H) or less (clone G).

Of the clones only $\mathrm{G}$ produced wingless males (Table 2 ), and clone B produced many oviparae but no males. Clone $\mathrm{B}$ produced no males not only at $20^{\circ} \mathrm{C}$, but also at

TABLE 1. Examples of the percentages of viviparae produced by clones of A.pisum at different photoperiods (each figure represents the progeny of about 15 females) at $20^{\circ} \mathrm{C}$.

\begin{tabular}{lccccccc}
\hline Photoperiod & \multicolumn{7}{c}{ Clone } \\
\cline { 2 - 7 } & $\mathrm{B}$ & $\mathrm{C}$ & $\mathrm{D}$ & $\mathrm{E}$ & $\mathrm{F}$ & $\mathrm{G}$ & $\mathrm{H}$ \\
\hline $0 \mathrm{~L}: 24 \mathrm{D}$ & 96.7 & 100.0 & 96.2 & 100.0 & 100.0 & - & 100.0 \\
2L $: 22 \mathrm{D}$ & 62.0 & 100.0 & 91.3 & 100.0 & 100.0 & 80.0 & 100.0 \\
4L $: 20 \mathrm{D}$ & 17.3 & 73.1 & 77.9 & 100.0 & 100.0 & 8.7 & 95.5 \\
$8 \mathrm{~L}: 16 \mathrm{D}$ & - & 0 & 21.4 & 15.5 & 24.1 & 2.5 & 0 \\
$10 \mathrm{~L}: 14 \mathrm{D}$ & 29.0 & 0 & 0.8 & 0.6 & 36.5 & 4.9 & 0 \\
$17 \mathrm{~L}: 7 \mathrm{D}$ & 66.8 & 100.0 & 100.0 & 100.0 & 100.0 & 15.5 & 100.0 \\
$18 \mathrm{~L}: 6 \mathrm{D}$ & 100.0 & 100.0 & 100.0 & 100.0 & 100.0 & 83.6 & 100.0 \\
\hline
\end{tabular}



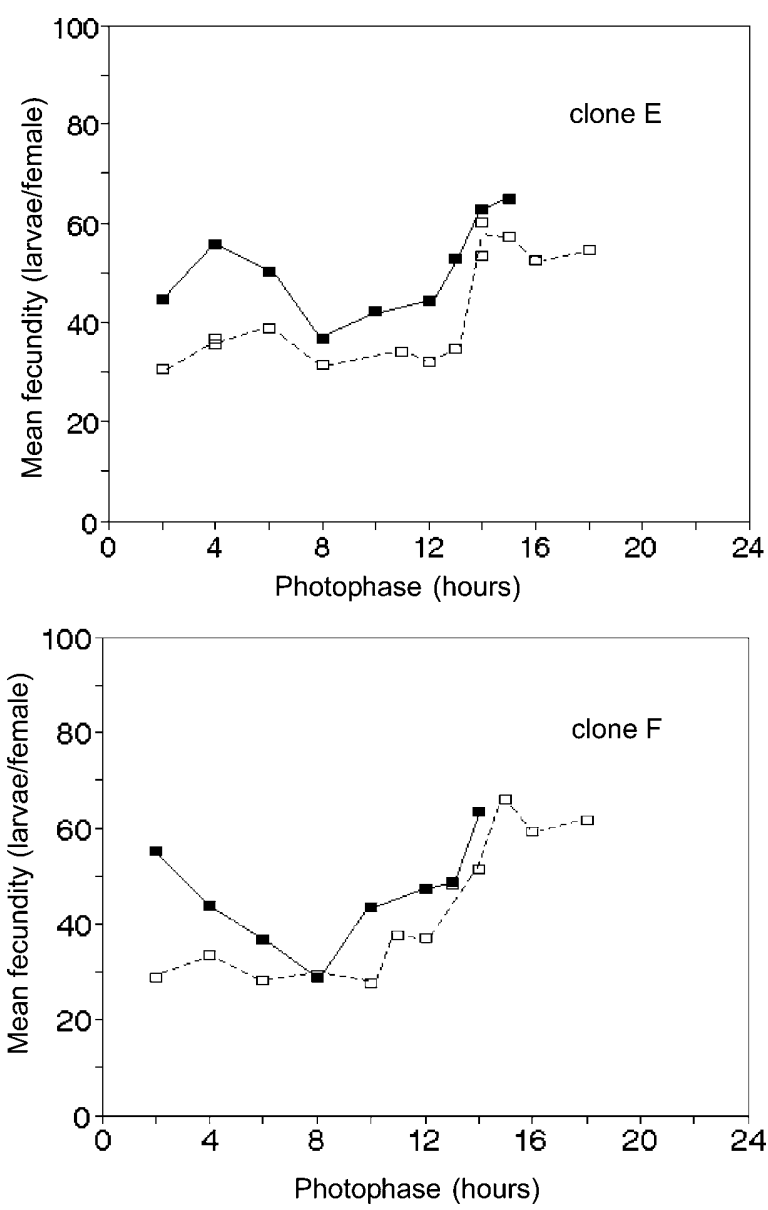

Fig. 2. The relationship between photoperiod and mean fecundity for apterae (filled squares, solid line) and alatae (empty squares, dashed line) of $A$. pisum (each value is the average of the results for about 15 females).

$15^{\circ} \mathrm{C}$. Oviparae of this unisexual clone mated with males of other clones and produced fertilized eggs.

\section{Intraclonal differences in morph production between apterae and alatae}

In summer aphid colonies consist of both apterae and alatae. The range of photoperiods suppressing the production of viviparae in alatae spread further both to the left and to the right, compared to that for apterae. Thus, as the natural day-length decreases alatae switch from parthenogenetic reproduction to mating and egg-laying earlier than their apterous sisters (Fig. 1).

Alatae produced fewer males and more oviparae than apterae. The limits of the photoperiods inducing the production of males and oviparae have different relative positions in alatae and apterae. In apterae, the production of males was induced by longer photoperiods than those inducing oviparae. In alatae, by contrast, the production of males was induced by shorter photoperiods than those inducing oviparae.

\section{Differences in the reproduction of apterae and alatae}

The fecundity of alatae was lower (Fig. 2), although they reproduced for longer than apterae and lived longer. The alatae lived for up to 45 days and the majority died
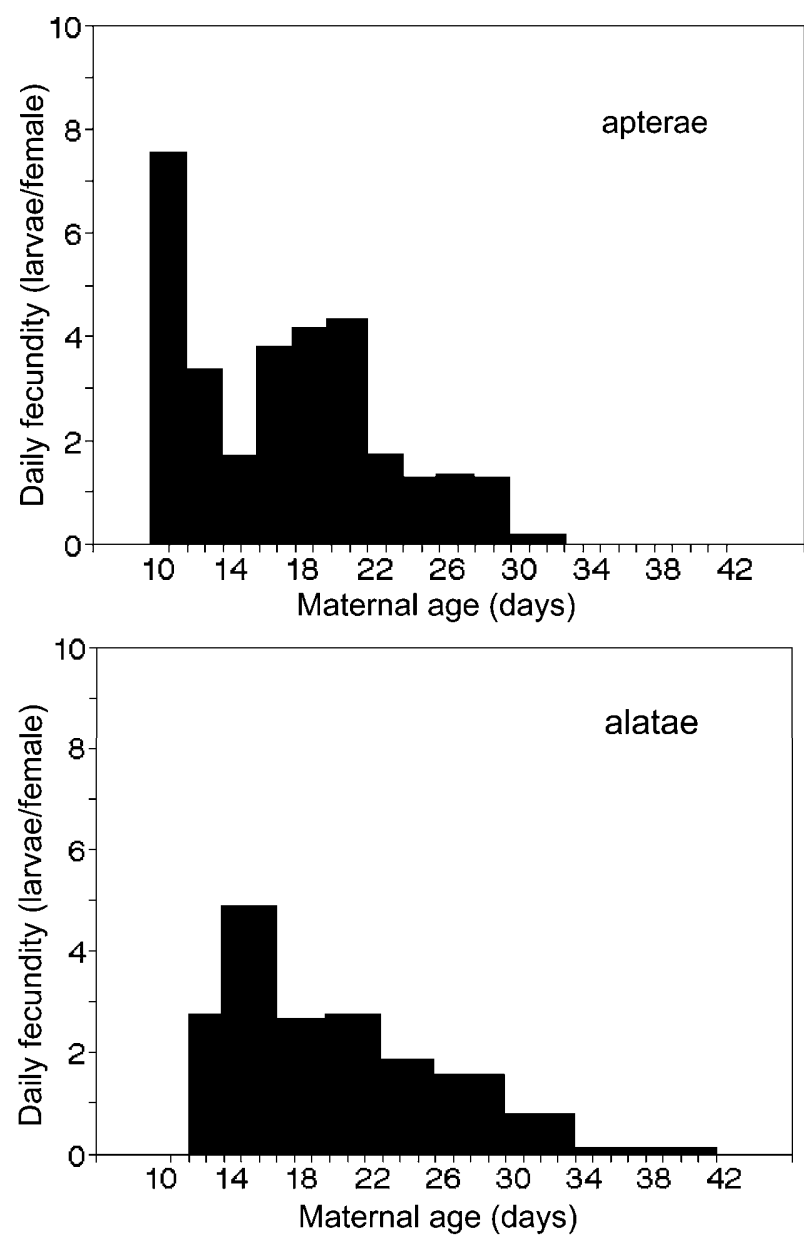

Fig. 3. Daily fecundity of apterae and alatae of A. pisum; clone $\mathrm{F}, 13 \mathrm{~L}$ : 11D (progeny of about 15 females in each case).

some days after the termination of reproduction, whereas half the apterae died between 16-24 days, depending upon photoperiod (Table 3). The most intensive larviposition was by females younger than 22 days (Fig. 3). Thus, although the most intensive larviposition occurred in the first 2 weeks of reproduction, both in apterae and alatae, half the apterae died before the end of this period. A very low fecundity (less than one larva per day) was observed during the final 5-7 days of reproduction in apterae and the final 10-14 days in alatae.

Reproduction in apterae began at between 9-10 days, and that of alatae, nearly 2 days later. These 2 days correspond to the migration period in nature, while in the experiment, the alatae actively walked on the walls of their cages and began larviposition at the age of 12 days. The males and females appeared in the progeny of individual parents sequentially rather than simultaneously (Tables 4-5). The temporary decrease in the daily fecundity, observed in apterae (Fig. 3), preceded the beginning of the production of males and corresponded to the reproductive pause, which occurs between the termination of female and beginning of male production. It commonly lasted for 2 days. In contrast, there was no distinct reproductive pause between the production of females and males in alatae; if present, it usually lasted less than a 
TABLE 2. Critical photoperiods and limits of the photoperiods, the maximal production of sexual morphs and morph of the males produced by apterae of clones $\mathrm{B}-\mathrm{H}$ of $A$. pisum at $20^{\circ} \mathrm{C}$.

\begin{tabular}{|c|c|c|c|c|c|c|c|}
\hline Clone & $\mathrm{B}$ & $\mathrm{C}$ & $\mathrm{D}$ & $\mathrm{E}$ & $\mathrm{F}$ & G & $\mathrm{H}$ \\
\hline $\begin{array}{l}\text { critPH for } q \text { morph } \\
\text { determination (at } \\
\text { natural PHs) }\end{array}$ & $\begin{array}{l}16.40 \mathrm{~L}: \\
7.20 \mathrm{D}\end{array}$ & $\begin{array}{l}12.30 \mathrm{~L}: \\
11.30 \mathrm{D}\end{array}$ & $\begin{array}{l}12.30 \mathrm{~L}: \\
11.30 \mathrm{D}\end{array}$ & $\begin{array}{l}11.30 \mathrm{~L}: \\
12.30 \mathrm{D}\end{array}$ & $\begin{array}{l}\text { 11L: } \\
\text { 13D }\end{array}$ & $\begin{array}{l}17.20 \mathrm{~L}: \\
6.40 \mathrm{D}\end{array}$ & $\begin{array}{l}12.30 \mathrm{~L}: \\
11.30 \mathrm{D}\end{array}$ \\
\hline $\begin{array}{l}\text { critPH for }+ \text { morph } \\
\text { determination (at } \\
\text { very short PHs) }\end{array}$ & 2L:22D & 5L:19D & 5L:19D & 7L:17D & 7L:17D & $\begin{array}{l}2.30 \mathrm{~L}: \\
21.30 \mathrm{D}\end{array}$ & 5L:19D \\
\hline $\begin{array}{l}\max . \% \text { ovipara } \\
\text { production, }(\mathrm{PH})\end{array}$ & $\begin{array}{c}88 \% \\
(9 \mathrm{~L}: 15 \mathrm{D}, \\
12.20 \mathrm{~L}: 11.40 \mathrm{D})\end{array}$ & $\begin{array}{c}74 \% \\
\text { (10L:14D) }\end{array}$ & $\begin{array}{c}70 \% \\
\text { (10L:14D) }\end{array}$ & $\begin{array}{c}46 \% \\
(10 \mathrm{~L}: 14 \mathrm{D})\end{array}$ & $\begin{array}{c}41 \% \\
(8 \mathrm{~L}: 16 \mathrm{D})\end{array}$ & $\begin{array}{c}91 \% \\
\text { (8L:16D) }\end{array}$ & $\begin{array}{c}78 \% \\
(11 \mathrm{~L}: 13 \mathrm{D})\end{array}$ \\
\hline $\begin{array}{l}\text { PH limits for } \\
\text { ovipara production }\end{array}$ & $\begin{array}{c}\text { 0L:24D- } \\
17.20 \mathrm{~L}: 6.40 \mathrm{D}\end{array}$ & $\begin{array}{l}\text { 2L:22D- } \\
\text { 14L:10D }\end{array}$ & $\begin{array}{l}0 \mathrm{~L}: 24 \mathrm{D}- \\
14 \mathrm{~L}: 10 \mathrm{D}\end{array}$ & $\begin{array}{l}\text { 4L:20D- } \\
\text { 13L:11D }\end{array}$ & $\begin{array}{l}\text { 6L:18D- } \\
\text { 12L:12D }\end{array}$ & $\begin{array}{l}\text { (shorter than } \\
\text { 2L:22D) } \\
-19 \mathrm{~L}: 5 \mathrm{D}\end{array}$ & 2L:22D-15L:9D \\
\hline $\begin{array}{l}\max . \% 0 \\
\text { production, } \\
(\mathrm{PH})\end{array}$ & no $\partial$ & $\begin{array}{c}44 \% \\
(14 \mathrm{~L}: 10 \mathrm{D})\end{array}$ & $\begin{array}{c}39 \% \\
\text { (13L:11D) }\end{array}$ & $\begin{array}{c}57 \% \\
(8 \mathrm{~L}: 16 \mathrm{D})\end{array}$ & $\begin{array}{c}59 \% \\
(12 \mathrm{~L}: 12 \mathrm{D})\end{array}$ & $\begin{array}{c}32 \% \\
\text { (18L:6D) }\end{array}$ & $\begin{array}{c}35 \% \\
(12 \mathrm{~L}: 12 \mathrm{D})\end{array}$ \\
\hline $\begin{array}{l}\text { PHic limits for } \delta \\
\text { production }\end{array}$ & no $\partial$ & $\begin{array}{l}\text { 2L:22D-15L:9D, } \\
\text { single } \delta \delta \text { at } \\
\text { 15L:9D, 16L:8D, } \\
\text { 18L:6D }\end{array}$ & $\begin{array}{l}\text { 2L:22D-15L:9D, } \\
\text { single } \$ \partial \text { at } \\
\text { 15L:9D, 17L:7D, } \\
\text { 18L:6D, 24L:0D }\end{array}$ & $\begin{array}{l}\text { 2L:22D } \\
-15 \mathrm{~L}: 9 \mathrm{D}\end{array}$ & $\begin{array}{l}\text { 2L:22D } \\
-15 \mathrm{~L}: 9 \mathrm{D}\end{array}$ & $\begin{array}{l}\text { (shorter than } \\
\text { 2L:22D) } \\
\text {-19L:5D }\end{array}$ & $\begin{array}{c}\text { (shorter than } \\
\text { 2L:22D)-16L:8D, } \\
\text { single } 0 \text { of at } \\
\text { 18L:6D }\end{array}$ \\
\hline morph of males & no $\partial$ & winged & winged & winged & winged & wingless & winged \\
\hline
\end{tabular}

critPH - critical photoperiod; PHs - photoperiods; max. \% - maximum production, $\%$ of all progeny

day. The first males appeared in the progeny of parents older than 14-15 days, both in apterae and alatae. Thus, the beginning of male production depended on maternal age, and not on the time since the onset of larviposition. The reproductive pause is probably obscured in alatae, because larviposition in alatae began 2 days later than in apterae.

\section{The effect of photoperiod on the age-dependent changes in the morph of the progeny}

The analysis of the progeny sequences of groups of parents revealed changes in the morph of the progeny, depending on photoperiod and maternal age (Fig. 4). The progeny of young aphids (both apterae and alatae) consisted only of females, as was the case for individual parents (Tables 4-5). Males first appeared in the progeny of 14-15-day old aphids. If conditions were favourable for the production of males, it lasted sometimes till the end of larviposition (clone F, apterous parents). If few males were produced they were born in the middle of the reproductive period and to only a few parents (clone F, alate parents). Oviparae also tended to be born in the middle of the reproductive period, like the males. Different

TABLE 3. Life span and duration of reproduction by apterae and alatae of $\mathrm{A}$. pisum at $20^{\circ} \mathrm{C}$ (each value represents the analysis of more than 8 samples of about 15 females reared at different photoperiods).

\begin{tabular}{lcccc}
\hline Clone & \multicolumn{2}{c}{ Clone E } & \multicolumn{2}{c}{ Clone F } \\
\hline parent morph & apterae & alatae & apterae & alatae \\
\hline $\begin{array}{l}\text { median life span } \\
\text { (days) }\end{array}$ & $20-23$ & $31->41$ & $16-24$ & $34->41$ \\
$\begin{array}{l}\text { age when } \\
\text { larviposition } \\
\text { ceased (days) }\end{array}$ & $27-34$ & $31-38$ & $25-34$ & $33-41$ \\
\hline a(the age at which 50\% died) & & & \\
\hline
\end{tabular}

short-day conditions induced different patterns of filial females at the beginning of the reproductive period. Photoperiods 10L : 14D-8L : 16D experienced by apterae of clone $F$ and 13L:11D-4L:20D by alatae of clone $F$ and $16 \mathrm{~L}: 8 \mathrm{D}-4 \mathrm{~L}: 20 \mathrm{D}$ by apterae of clone $\mathrm{B}$ induced the production of oviparae from the very onset of larviposition (Fig. 4). Photoperiods 11L : 13D-6L : 18D experienced by alatae of clone $F$ and $14 \mathrm{~L}: 10 \mathrm{D}-9 \mathrm{~L}: 15 \mathrm{D}$ by apterae of clone $\mathrm{B}$ induced only oviparae in the initial batch of progeny. This variability in morph production patterns at different photoperiods reflects clone-specific photoperiodic effect on sex and female morph determination. The onset and duration of the production of a certain morph depended also upon the morph of the parent, whether apterous or alate.

As a rule, occasional viviparae appeared in the end of reproductive sequences, that is, when parents were older than 28-30 days. The tendency to produce initial and final batches of viviparae in short-day conditions was common in both apterae and alatae. It was most evident in the unisexual clone B. The switch in female morph production tended to occur twice during larviposition - at the beginning (vivipara to ovipara) and at the end (ovipara to vivipara).

\section{DISCUSSION}

The long-day induction of the female morph is well known in aphids (Lees, 1966; Beck, 1980). According to the classical view, the critical photoperiod depends on latitude (Danilevski, 1961), but the differences in critical day-length of the clones collected near St.Petersburg reflect a local intrapopulation polymorphism in sexual morph production. The variation in the critical photoperiod from $11 \mathrm{~L}: 13 \mathrm{D}$ to $12.30 \mathrm{~L}: 11.30 \mathrm{D}$ (in clones $\mathrm{C}, \mathrm{D}$, $\mathrm{E}, \mathrm{F}, \mathrm{H})$ is probably inherited. The inheritance of the pho- 
TABLE 4. Progeny sequences in the first week of reproduction of individual apterae of $A$. pisum from clone $\mathrm{E}$ at 10L:14D.

\begin{tabular}{lccccccc}
\hline Parents, & \multicolumn{7}{c}{ Maternal age, days } \\
\cline { 2 - 8 } & $10-11$ & 12 & 13 & 14 & 15 & 16 & 17 \\
\hline 1 & 0 & - & - & $\mathrm{m}$ & $\mathrm{m}$ & $\mathrm{m}$ & $\mathrm{m}$ \\
2 & 0 & - & - & $\mathrm{m}$ & $\mathrm{m}$ & $\mathrm{m}$ & $\mathrm{m}$ \\
3 & 0 & - & - & $\mathrm{m}$ & $\mathrm{m}$ & $\mathrm{m}$ & $\mathrm{m}$ \\
4 & $\mathrm{o}$ & - & - & $\mathrm{m}$ & $\mathrm{m}$ & $\mathrm{m}$ & $\mathrm{m}$ \\
5 & $\mathrm{o}$ & $\mathrm{o}$ & $\mathrm{o}$ & $\mathrm{m}$ & $\mathrm{m}$ & $\mathrm{m}$ & $\mathrm{m}$ \\
6 & $\mathrm{vo}$ & $\mathrm{o}$ & - & $\mathrm{m}$ & $\mathrm{m}$ & $\mathrm{m}$ & $\mathrm{m}$ \\
7 & $\mathrm{vo}$ & $\mathrm{o}$ & $\mathrm{o}$ & - & - & $\mathrm{m}$ & $\mathrm{m}$ \\
8 & $\mathrm{o}$ & $\mathrm{o}$ & - & - & $\mathrm{m}$ & $\mathrm{m}$ & $\mathrm{m}$ \\
9 & $\mathrm{o}$ & $\mathrm{o}$ & - & $\mathrm{m}$ & $\mathrm{m}$ & $\mathrm{m}$ & $\mathrm{m}$ \\
\hline
\end{tabular}

$\mathrm{v}$ - viviparae, $\mathrm{o}$ - oviparae, $\mathrm{m}$ - males

toperiodic response in aphids is poorly studied with only a single report for the bird cherry aphid, Rhopalosiphum padi (Lushai et al., 1996). Three parent clones of $R$. padi with critical photoperiods (authors revealed critical nightlengths) for gynopara production of $11.50 \mathrm{~L}: 12.10 \mathrm{D}, 12 \mathrm{~L}$ $: 12 \mathrm{D}$, and $12.45 \mathrm{~L}: 11.15 \mathrm{D}$ were crossed and the critical photoperiods of some of the crosses fell outside that of the parental clones. The difference in the critical photoperiods of the filial clones and between filial and parental clones of $R$. padi were not more than 2 hours, which is similar to the variation in critical photoperiods near to 12L : 12D (11L : 13D-12.30L : 11.30D) observed in the present study.

However, the difference between the $12 \mathrm{~L}: 12 \mathrm{D}$ critical photoperiod of clones C, D, E, F, H and the 17L : 7D critical photoperiod of clones $B, G$ is so great that it requires another explanation. Migration is thought to account for local polymorphism in the photoperiodic response of aphids (Smith \& MacKay, 1989a, 1990). The photoperiods at $65^{\circ} \mathrm{N}$ and even at $70^{\circ} \mathrm{N}$ would induce clones B and $\mathrm{G}$ to produce sexuals in August or early September (Sharonov, 1945). Therefore, these clones may originate from higher latitudes than St.Petersburg $\left(60^{\circ} \mathrm{N}\right)$.

On the other hand, clones $\mathrm{B}$ and $\mathrm{G}$ in the same region will produce males and oviparae earlier in the summer than the clones with a 12-hour critical photoperiod. Therefore, the sexuals of these clones are likely to mate with each other. Thus, the differences in critical photoperiod probably favour intraspecific isolation. A. pisum is thought to consist of a number of forms of unknown taxonomic status, which are associated with different host plants (Müller, 1962, 1980; Posylaeva, 1981). Many authors regarded the form that feeds on peas during summer as a subspecies, A. p. destructor Johnson 1900 (Müller, 1980). However, although all clones used in this study are morphologically similar and were collected from peas, it is possible that they belonged to different taxonomical forms of pea aphid. It must be stressed that all clones in this study with a critical photoperiod of about 12L : 12D produced winged males (as has been reported for the form from peas), whereas clones with a critical photoperiod of about 17L : 7D produced wingless
Table 5. Progeny sequences in the first week of reproduction of individual alatae of $A$. pisum from clone $\mathrm{E}$ at $10 \mathrm{~L}$ : 14D.

\begin{tabular}{|c|c|c|c|c|c|c|c|}
\hline \multirow{2}{*}{$\begin{array}{l}\text { Parents, } \\
\text { No. }\end{array}$} & \multicolumn{7}{|c|}{ Maternal age, days } \\
\hline & $10-11$ & 12 & 13 & 14 & 15 & 16 & 17 \\
\hline 1 & - & 0 & o & o & o & $\mathrm{m}$ & $\mathrm{m}$ \\
\hline 2 & - & 0 & 0 & $\mathrm{~m}$ & - & $\mathrm{m}$ & $\mathrm{m}$ \\
\hline 3 & - & o & o & 0 & 0 & 0 & 0 \\
\hline 4 & - & o & o & o & o & o & o \\
\hline 5 & - & o & o & o & o & $\mathrm{m}$ & $\mathrm{m}$ \\
\hline 6 & - & o & o & o & o & $\mathrm{om}$ & $\mathrm{m}$ \\
\hline 7 & - & o & o & o & $\mathrm{m}$ & $\mathrm{m}$ & $\mathrm{m}$ \\
\hline 8 & - & o & o & o & $\mathrm{m}$ & $\mathrm{m}$ & 0 \\
\hline 9 & - & o & o & - & $\mathrm{m}$ & $\mathrm{m}$ & $\mathrm{m}$ \\
\hline 10 & - & 0 & o & 0 & $\mathrm{om}$ & $\mathrm{m}$ & $\mathrm{m}$ \\
\hline 11 & - & - & o & o & $\mathrm{m}$ & $\mathrm{m}$ & $\mathrm{m}$ \\
\hline 12 & - & o & o & o & o & $\mathrm{m}$ & $\mathrm{m}$ \\
\hline 13 & - & 0 & o & $\mathrm{om}$ & $\mathrm{om}$ & $\mathrm{om}$ & $\mathrm{m}$ \\
\hline 14 & - & 0 & 0 & 0 & o & $\mathrm{m}$ & $\mathrm{m}$ \\
\hline
\end{tabular}

o- oviparae, $\mathrm{m}$ - males

males (clone G) or no males at all (clone B). However, according to Smith and MacKay (1989b), who described clones with both winged and wingless males, the morph of males does not necessarily indicate a taxonomically different form within A. pisum. Literature on the variability in the photoperiodic response of holocyclic clones of aphids from different host plants is scarce. In Schizaphis graminum single clones of biotypes $\mathrm{C}$ and $\mathrm{E}$ differ by $15 \mathrm{~min}$ in the photoperiods for male induction and do not differ in the photoperiods for ovipara induction (Eisenbach \& Mittler, 1987). In another report, the groups to which the clones of $S$. graminum could be assigned on the basis of their photoperiodic responses, differed from that based on the performance of these clones on different varieties of sorghum (Mittler \& Gorder, 1991). Similarly in A. pisum, Chmyr' and Kolesova (1988) report that aphids from clover begin producing oviparae at longer days than those from peas. The strong tendency of $A$. pisum from peas to reproduce parthenogenetically is wellknown. However, clover is not a suitable host plant for $A$. pisum from peas, and vice versa. A special study of host plant preference is needed to determine whether the $12 \mathrm{~L}$ : 12D and 17L : 7D critical photoperiods are a consequence of migration or an intraspecific difference.

The unisexual clone B was described in detail by the author in 1997 (Erlykova, 1997) and there are still no reports in the literature of other aphid clones with an annual cycle of this type. In the clones that produced few males the photoperiodic response for male induction is not defined to be threshold-like as there was little change in percentage of males produced. The photoperiodic limits for male production differed from those for ovipara production by less than an hour to more than 2 hours, and were associated with clone-specific abundance of males. Male production by apterae was always induced by photoperiods longer than that required for ovipara 
clone $\mathrm{F}$ apterous parents

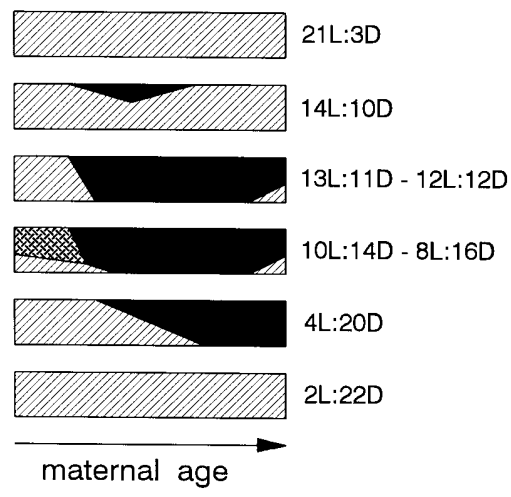

clone B apterous parents

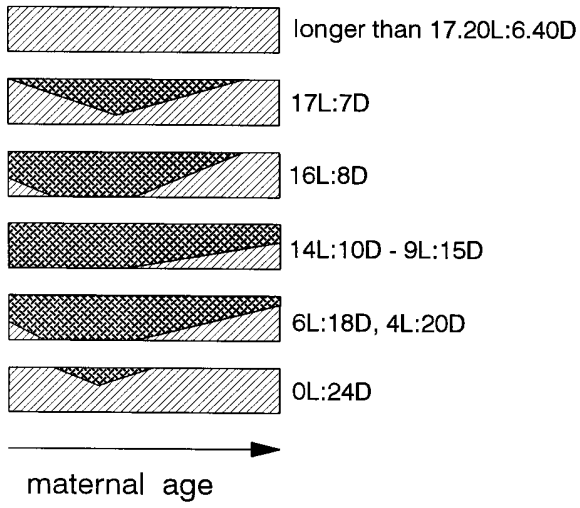

clone $\mathrm{F}$ alate parents

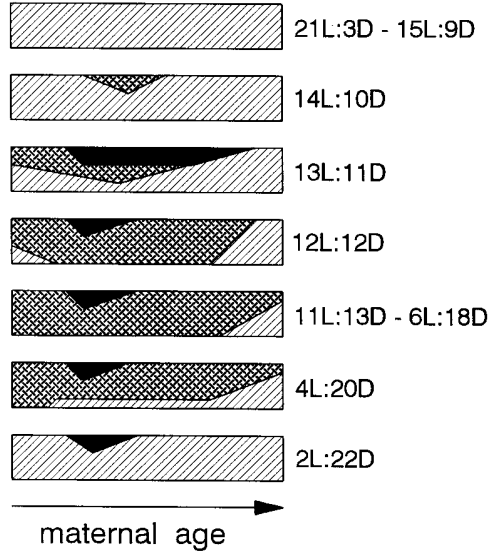

- VIVIPARAE

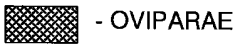

Fig. 4. Age-dependent progeny pattern for viviparae of $A$. pisum reared at different photoperiods.

production. The relative position of the photoperiodic limits for male and ovipara production always had the opposite trend in alatae. The same was reported by Vaz Nunes and Hardie (1996) for a pink clone of pea aphid.

The critical photoperiods for female morph determination in apterae and alatae differed distinctly (Fig. 1) and demonstrate the general trend, that if the right threshold shifts to the right along the photoperiodic scale, the left one correspondingly shifts to the left (Danilevski, 1961).
This regularity is also revealed by comparing the mean of the two critical photoperiods (at natural and extremely short photoperiods) in clones $\mathrm{C}, \mathrm{D}, \mathrm{E}, \mathrm{F}$, and $\mathrm{H}$ (about 12L : 12D and 5L : 19D-7L : 17D) and in clones $B$ and $G$ (about 17L : 7D and 2L : 22D).

In this study, there were no differences in the agedependent appearance of certain morphs in the progeny sequences of apterae and alatae, which contrasts with the findings of MacKay et al. (1983). The age-dependent progeny patterns of apterae described in the present study are consistent with other reports (Kenten, 1955; Lamb \& Pointing, 1975; Sharma et al., 1975; MacKay, 1987; Lees, 1989) and were previously discussed in detail by the author (Erlykova, 1997, 1999). However, it must be noted that the tendency in this study for both apterae and alatae to produce initial and final batches of viviparae contrasts with the findings of MacKay et al. (1983) and Vaz Nunes \& Hardie (1996) who found no viviparae production at the end of progeny sequences of alatae.

The tendency to produce initial and final batches of viviparae seems to reflect age-dependent endogenous changes in the hormonal titres of the parents. The tendency of the same parent to produce different morphs possibly reflects a very flexible hormonal equilibrium in this species. The changes in the age-dependent progeny pattern allow us to estimate the relative strength of a wide range of photoperiods without transferring the parents from long day to different short days or vice versa, as done by Lees (1963) and by Zaslavski \& Fomenko (1983) in their experiments on the vetch aphid Megoura viciae.

The peculiarities of the photoperiodic response and reproduction of apterae and alatae are consistent with their different ecological roles. The apterous viviparae are believed to be mainly adapted for reproduction. Therefore, it would be advantageous if they were able to reproduce parthenogenetically for the longest period possible. The wide range of photoperiods inducing the production of viviparae, combined with high fecundity, serve this purpose.

The ecological role of alatae is dispersal and colonizing new host plants. It is therefore possible that they will reproduce in an environment different from that from which they originated. To ensure reproduction under unfavourable conditions, it would be adaptive to possess a physiological response enhancing oviposition. This is supported by the production of oviparae over a wide range of photoperiods. The oviparae produced by alatae that migrate probably mate with native males which are born earlier than the oviparae of the same clones. As alatae produce very few males this may enhance crossing between clones from different populations. The longevity of alate viviparae is associated with their need to fly and/or may compensate for their low fecundity.

ACKNOWLEDGEMENTS. The author gratefully acknowledges the assistance of G.M. Shkarlat and L.N. Fedorova with the experiments, and to S.Ya. Reznik for commenting on the manuscript. I am indebted to unknown referees for commenting and linguistic refinement of the original manuscript. The study 
was financially supported by the Russian Foundation for Basic Research, grant No. 98-04-49684.

\section{REFERENCES}

Beck S.D. 1980: Insect Photoperiodism. Acad. Press, New York, $387 \mathrm{pp}$.

BLACKMAN R.L. 1971: Variation in the photoperiodic response within natural populations of Myzus persicae (Sulz.). Bull. Entomol. Res. 60: 533-546.

Chmyr' P.G. \& Kolesova D.A. 1988: Photoperiodic responses of pea aphid Acyrthosiphon pisum (Homoptera: Aphididae) from different host plants. Zool. Zh. 67: 466-470. [in Russian]

Danilevski A.S. 1961: Photoperiodism and Seasonal Development of Insects. Izd. Len. Gos. Univ., Leningrad, 243 pp. [in Russian]

Dedryver C.A., Le Gallic J.F., Gauthiter J.P. \& Simon J.C. 1998: Life cycle of the cereal aphid Sitobion avenae F.: polymorphism and comparison of life history traits associated with sexuality. Ecol. Entomol. 23: 123-132.

Eisenbach J. \& Mittler T.E. 1987: Polymorphism of biotypes E and $\mathrm{C}$ of the aphid Schizaphis graminum (Homoptera: Aphididae) in response to different scotophases. Environ. Entomol. 16: 519-523.

ERLYKova N.N. 1997: Peculiarities of the photoperiodic response of the unisexual clone of the pea aphid Acyrthosiphon pisum Harris (Homoptera: Aphididae), Entomol. Obozr. 76: 497-507. [in Russian, English translation: Yerlykova N.N. 1998: Entomol. Rev. 76: 301-308.]

ERLYKova N.N. 1999: Effect of photoperiod and maternal age on the progeny pattern of the pea aphid Acyrthosiphon pisum Harris (Homoptera: Aphididae) from the Volga area. Entomol. Obozr. 78: 275-286. [in Russian, English translation: Entomol. Rev. 79: 1098-1106.]

Kenten J. 1955: The effect of photoperiod and temperature on reproduction in Acyrthosiphon pisum (Harris) and the form produced. Bull. Entomol. Res. 46: 599-624.

LAMB R.J. \& MacKay P.A. 1997: Photoperiodism and life cycle plasticity of an aphid, Macrosiphum euphorbiae (Thomas), from Central North America. Can. Entomol. 129: 1035-1048.

LAMr R.J. \& Pornting P.J. 1972: Sexual morph determination in the pea aphid, Acyrthosiphon pisum. J. Insect Physiol. 18: 2029-2042

LAvB R.J. \& Pornting P.J. 1975: The reproductive sequence and sex determination in the aphid Acyrthosiphon pisum. J. Insect Physiol. 21: 1443-1446.

LeEs A.D. 1959: The role of photoperiod and temperature in the determination of parthenogenetic and sexual forms in the aphid Megoura viciae Buckton - I. The influence of these factors on apterous virginoparae and their progeny. J. Insect Physiol. 3: 92-117.

LEES A.D. 1963: The role of photoperiod and temperature in the determination of parthenogenetic and sexual forms in the aphid Megoura viciae Buckton - III. Further properties of the maternal switching mechanism in apterous aphids. J. Insect Physiol. 9: 153-164.

LeEs A.D. 1966: The control of polymorphism in aphids. $A d v$. Insect Physiol. 3: 207-277.

LeEs A.D. 1989: The photoperiodic responses and phenology of an English strain of the pea aphid Acyrthosiphon pisum. Ecol. Entomol. 14: 69-78.

Lushai G., HARDie J. \& Harrington R. 1996: Inheritance of photoperiodic response in the bird cherry aphid, Rhopalosiphum padi. Physiol. Entomol. 21: 297-303.
MacKay P.A. 1987: Production of sexual and asexual morphs and changes in reproductive sequence associated with photoperiod in the pea aphid, Acyrthosiphon pisum (Harris). Can. J. Zool. 65: 2602-2606.

MacKay P.A. 1989: Clonal variation in sexual morph production in Acyrthosiphon pisum (Homoptera: Aphididae). Envir. Entomol. 18: 558-562.

MacKay P.A., Reeleder D.J. \& Lamb R.J. 1983: Sexual morph production by apterous and alate viviparous Acyrthosiphon pisum (Harris) (Homoptera: Aphididae). Can. J. Zool. 61: 952-957.

MitTler T.E. \& GoRder N.K.N. 1991: Variation between clones of Schizaphis graminum (Homoptera: Aphididae) in the photoperiodic induction of sexual morphs. Envir. Entomol. 20: 433-440.

Mittler T.E. \& Wilhort L. 1990: Sexual morph production by two regional biotypes of Myzus persicae (Homoptera: Aphididae) in relation to photoperiod. Envir. Entomol. 19: $32-35$.

Müller F.P. 1962: Biotypen und Unterarten der "Erbsenblattlaus" Acyrthosiphon pisum (Harris). Z. Plantkrank. Pflschutz. 69: 129-136.

MüLLER F.P. 1980: Wirtspflanzen, Generationenfolge und reproduktive Isolation infraspezifischer Formen von Acyrthosiphon pisum. Entomol. Exp. Appl. 28: 145-157.

Posylaeva G.A. 1981: Colour forms of the pea aphid. Trudy Vsesoyuz. Entomol. Obshch. 63: 45-47. [in Russian]

Sharma M.L., LARrIVÉE J.M. \& ThÉRIAULt L.M. 1975: Séquences de descendence des formes sexuées chez le puceron du pois Acyrthosiphon pisum (Homoptera: Aphididae) en relation avec la durée des photopériodes. Can. Entomol. 107: $1063-1067$.

Sharonov V.V. 1945: Tables for Estimation of Natural Degree of Illumination and Visibility. Izd. Akad. Nauk SSSR, Moscow-Leningrad, 194 pp. [in Russian]

Sмith M.A.H. \& MacKay P.A. 1989a: Seasonal variation in the photoperiodic responses of a pea aphid population: evidence for long-distance movements between populations. Oecologia 81: $160-165$.

SмITH M.A.H. \& MacKay P.A. 1989b: Genetic variation in male alary dimorphism in populations of pea aphid, Acyrthosiphon pisum. Entomol. Exp. Appl. 51: 125-132.

Sмiтн M.A.H. \& MacKay P.A. 1990: Latitudinal variation in the photoperiodic responses of populations of pea aphid (Homoptera: Aphididae). Envir. Entomol. 19: 618-624.

TAKADA H. 1988: Interclonal variation in the photoperiodic response for sexual morph production of Japanese Aphis gossypii Glover (Hom.: Aphididae). J. Appl. Entomol. 106: 188-197.

VAz Nunes M. \& HaRdIE J. 1996: Differential photoperiodic responses in genetically identical winged and wingless pea aphids, Acyrthosiphon pisum, and the effect of day length on wing development. Physiol. Entomol. 21: 339-343.

Zaslavski V.A. 1988: Insect Development. Photoperiodic and Temperature Control. Springer-Verlag, Berlin, Heidelberg, New York, $187 \mathrm{pp}$.

ZASLAVSKI V.A. \& FomenKo R.B. 1983: Quantitative perception of photoperiod in the aphid Megoura viciae Buckt. (Homoptera: Aphididae). Entomol. Obozr. 62: 433-441. [in Russian]

Zaslavski V.A. \& Fomenko R.B. 1986: Effect of the temperature on the photoperiodic response in the aphid Megoura viciae Buckt. (Homoptera, Aphididae). Entomol. Obozr. 65: 672-676. [in Russian]

Received December 10,2001; revised August 14, 2002; accepted November 8, 2002 